\title{
The Software for Composition of Some Natural Languages' Words
}

\author{
Jemal Antidze, Nana Gulua, and Irakli Kardava
}

\begin{abstract}
Machine translation from any language into another requires composition of a word-form by giving its unchanged part and morphological categories. Besides this, for distance studying Natural language and make assistant computer mean for teaching the morphology of some languages to secondary school pupils, it is necessary by using unchanged part of given word to get by the computer all grammatically right word-forms. For solving all these problems, we have developed the software, by which it is possible to solve mentioned problems for languages like Georgian. Besides this, for solving such problems of artificial intelligence, which requires composing of natural language's word-form by using the information defining this word-form, it is convenient to use the software developed by us.
\end{abstract}

Index Terms-Feature structures, form, program sign, software.

\section{INTRODUCTION}

The developed software represents set of programs, by which it is possible with unchanged part of a word and morphological categories to get appropriate grammatically right word-form or word-forms if such exist. Otherwise we shall get notification, which grammatical categories are not correct or the unchanged part of the word is not in data base. Also with this software it is possible by unchanged part of a word get all possible grammatically right word-forms. This used approach is based on description of natural language morphology by using formal grammar and characterizing symbols of grammar with feature structures.

For description natural language morphology we use special type of context free grammar [1], [2] which describes all correct natural language word-forms. With given unchanged part and its features existed in database, also with given morphological categories (in the case of first problem) we compose morpheme classes and their representatives, which must be in related word-forms [3], [4]. We demonstrate application of the software for Georgian language. Using of the software is effective for languages, which have developed morphology like Georgian. For composing features of unchanged part of the word we use Georgian language grammar [5] and D. Melikishvili classification for verbs [6], [7].

Manuscript received February 10, 2013; revised April 25, 2013.

Jemal Antidze is with I. Javakhishvili Tbilisi State University, I.Vekua Scientific Institute of Applied Mathematics, University 2, Tbilisi, 0186, Georgia (e-mail: jeantidze@yahoo.com).

Nana Gulua and Irakli Kardava are with Sokhumi State University, Politkovskaia 9, Tbilisi, 0186, Georgia (e-mail: ngulua7@)mail.ru, sokhummi@yahoo.com).

\section{SOFTWARE DESCRIPTION}

Software uses the database created by us. In it the information is represented by tables.

In main tables there are written down unchanged parts of words and their features. For each part of speech there are used different tables. For example, in main tables of verbs there is written down root, type, prefix and vowel prefixes, see Table I. To this table is connected the table, which consists of persons, numbers and so on - all of those elements, which are necessary to get grammatically correct word-form, see Table II. The same principle is used for other parts of speech.

In order to, that software will give us the result we must to give it unchanged part of searched word. If it is found in the database, it applies to appropriate table, process it and gives all grammatically right forms. If the entered unchanged part can't be found in database or it is indicated incorrectly, there will appear appropriate notification, which will request to change the sent unchanged part.

By using the software, it is possible get all grammatically right forms of any Georgian word and one of its advantage is, that the information is compactly written down in computer memory.

\section{SOFTWARE DESIGN}

Main window of the software looks as following (see Table III):

User can write down unchanged part of interesting word in the special field for this purpose. After clicking on the confirm button software should give result or results. See Table IV.

If the unchanged part of the word will be the verb's root, there will opened new window, where this given verb should be conjugated and arranged in accordance of diathesis, class, series, row, person and number. Each new window consists of generated verb's type name.

Herewith it is possible change of prefixes and vowel prefixes, if the given verb gives the opportunity. See Table V.

If the verb has several types, then software should open the window for each type.

There are cases, when the verb is used as the noun. For example let's take the verb shown in the picture - "write", if we take it as noun "write", then it is considered exactly as noun. Our software at this time declines the unchanged part "write" as verb, with foreseeing all its types and in parallel it declines it as noun. Analogically the same should we get for other parts of speech.

Software can solve the second problem; such is to 
establish word-form with indication unchanged part of the word and morphological categories. See Table VI.

TABLE I: DESCRIPTION OF A VERB'S PARTS

\begin{tabular}{|l|l|l|l|l|l|l|l|l|l|l|}
\hline root of verb & type & preverb1 & preverb2 & preverb3 & preverb4 & preverb5 & preverb6 & vowelprefix1 & $\begin{array}{l}\text { vowel } \\
\text { prefix2 }\end{array}$ & $\begin{array}{l}\text { vowel } \\
\text { prefix3 }\end{array}$ \\
\hline nt & diath2-class13-type1 & a & da & cha & null & null & null & i & e & null \\
\hline
\end{tabular}

TABLE II: DESCRIPTION OF A VERB-FORMS

\begin{tabular}{|l|l|l|l|l|l|}
\hline ID & entry1 & entry2 & entry3 & entry4 & entry5 \\
\hline 1 & $\mathrm{v}$ & ebi & null & null & $\mathrm{t}$ \\
\hline 2 & null & ebi & null & null & $\mathrm{t}$ \\
\hline 3 & null & eb & a & null & ian \\
\hline 4 & $\mathrm{v}$ & ebodi & null & null & $\mathrm{t}$ \\
\hline 5 & null & ebodi & null & null & $\mathrm{t}$ \\
\hline 6 & null & ebod & a & null & nen \\
\hline 7 & $\mathrm{v}$ & ebode & null & null & $\mathrm{t}$ \\
\hline 8 & null & ebode & null & null & $\mathrm{t}$ \\
\hline 9 & null & ebod & es & null & nen \\
\hline
\end{tabular}

TABLE III: MAIN WINDOW FOR NOUNS

\begin{tabular}{|l|l|l|l|l|l|}
\hline \multicolumn{2}{|c|}{ enter word here } & Burt & & preposition & second plural \\
\hline & singular & preposition & plural & & \\
\hline nominative & & & & & \\
\hline ergative & & & & & \\
\hline dative & & & & & \\
\hline genitive & & & & & \\
\hline ablative & & & & & \\
\hline condition & & & & & \\
\hline vocative & & & & & \\
\hline
\end{tabular}

TABLE IV: WORD-FORMS OF GIVEN NOUN

\begin{tabular}{|c|c|c|c|c|c|}
\hline \multicolumn{2}{|r|}{ enter unchanged part here } & \multirow{2}{*}{$\begin{array}{l}\text { burt } \\
\text { preposition }\end{array}$} & \multicolumn{2}{|r|}{ choose specific form here } & \multirow[b]{2}{*}{ second plural } \\
\hline & singular & & plural & particle & \\
\hline nominative & burt-i & burt-i-vit & burt-eb-i & burt-eb-i-vit & burt-n-i \\
\hline ergative & burt-ma & & burt-eb-ma & & burt-t-a \\
\hline dative & burt-s & \multirow{4}{*}{$\begin{array}{l}\text { burt-is-tvis } \\
\text { burt-is-gan burt-is-ken } \\
\text { burt-is-ebr } \\
\text { burt-tan }\end{array}$} & burt-eb-s & burt-eb-s-a-vit & burt-t-a \\
\hline genitive & burt-is & & burt-eb-is & burt-eb- is-tvis & burt-t-a \\
\hline ablative & burt-it & & burt-eb-it & burt-eb-i-turt & --- \\
\hline condition & burt-ad & & burt-eb-ad & burt-eb-a-mde & $\begin{array}{ll}-- \\
--\end{array}$ \\
\hline vocative & burt-o & & burt-eb-o & & burt-n-o \\
\hline
\end{tabular}

TABLE V: WORD-FORMS FOR GIVEN VERB

\begin{tabular}{|c|c|c|c|c|c|}
\hline \multicolumn{4}{|c|}{ diathesis 2 , paradigm 13, type 1 (Name of Type) } & \multicolumn{2}{|c|}{ choose } \\
\hline singular & plural & & & prefix of verb & vowel prefix2 \\
\hline & & & & da & $\mathrm{i}$ \\
\hline \multicolumn{3}{|c|}{ I series, present group } & \multicolumn{3}{|c|}{ II series } \\
\hline present tense & continuous tense & $\begin{array}{l}\text { connective present } \\
\text { tense }\end{array}$ & non-continuous & II connective & \\
\hline v-i-nt-eb-i & v-i-nt-eb-od-i & v-i-nt-eb-od-e & da-v-i-nt-e & da-v-i-nt-o & \\
\hline \multicolumn{3}{|c|}{ future tense group } & \multicolumn{3}{|c|}{ III series } \\
\hline da-v-i-nt-eb-i & da-v-i-nt-eb-od-i & da-v-i-nt-eb-od-e & da-v-nt-eb-ul-var & da-v-nt-eb-ul-ikavi & da-v-nt-eb-ul-v-iko \\
\hline
\end{tabular}


As it is shown from the table, there is given two opportunities, first is to get concrete forms of noun, and the second to get concrete forms of the verb. Let's discuss each of them successively. The first line gives opportunity to get the word-forms of the noun which is interested for us see Table VII.
TABLE VI: WINDOW FOR CHOICE OF A NOUN OR VERB

\begin{tabular}{|l|l|}
\hline $\begin{array}{l}\text { To get concrete word-form, choose speech part from } \\
\text { menu below: }\end{array}$ & \\
\hline & noun \\
\cline { 2 - 2 } & verb \\
\hline
\end{tabular}

TABLE VII: CHOICE OF MORPHOLOGICAL CATEGORIES FOR DESIRED WORD-FORM

\begin{tabular}{|c|c|c|c|}
\hline \multicolumn{3}{|c|}{ Enter desired unchanged part of a word here } & \\
\hline \multicolumn{4}{|c|}{ Choose appropriated morphological categories: } \\
\hline case & number & preposition & particle \\
\hline $\begin{array}{l}\text { nominative } \\
\text { ergative } \\
\text { dative } \\
\text { genitive } \\
\text { instrumental } \\
\text { situate } \\
\text { vocative }\end{array}$ & $\begin{array}{l}\text { singular } \\
\text { plural } \\
\text { second plural }\end{array}$ & $\begin{array}{ll}\text { vit } & \text { ebr } \\
\text { tan } & \text { tana } \\
\text { ze } & \text { urt } \\
\text { shi } & \\
\text { idan } & \\
\text { tvis } & \text { mde } \\
\text { gan } & \end{array}$ & $\begin{array}{l}\text { c } \\
\text { da } \\
\text { ve } \\
\text { a } \\
\text { o } \\
\text { metqi }\end{array}$ \\
\hline
\end{tabular}

If right preposition or particle is not added to any of case (which is marked by the user from the list), software will give notification, that the given information is not correct.

Analogically, we can recall interface which gives concrete forms of verbs, by clicking button "verbs" in the list. See Table VIII.

Different from nouns, verbs may have some types, in such cases software gives opportunity check number of types and select desirable type.

In the case, when there is not preliminary known number of type and after putting unchanged part of the word, there was confirmed generation, there will automatically opened notification window, which says us, that this verb have type more than one and it is inevitably necessary to select one concrete. See Table IX.

TABLE VIII: WINDOW FOR FIXING OF A VERB'S MORPHOLOGICAL CATEGORIES

\begin{tabular}{|l|l|l|}
\hline \multicolumn{3}{|c|}{ I series, present tense group } \\
\hline present tense & continuous tense & connective present tense \\
\hline 1 & $*$ & $*$ \\
\hline 2 & $*$ & $*$ \\
\hline 3 & $*$ & $*$ \\
\hline
\end{tabular}

TABLE IX: CHOICE OF ROOT'S TYPE

The entered stem has 10 different types, please select the appropriate button for chosen type

\section{CONCLUSION}

Thus, created software is used to get all word-forms from unchanged part of the word, also to get the word-form in accordance unchanged part of the word and morphological categories.

Software parts are written in c\# language and its design is realized by using visual studio 2008 express edition.

\section{REFERENCES}

[1] A. Acho and J. Ulman, The Theory of Parsing, Translation and Compiling, vol. 1, USA: Englewood Cliffs, 1972.

[2] J. Antidze, Teory of formal grammars and languages, computer modeling of natural languages, Tbilisi, Georgia: Nekeri, 2009.

[3] J. Antidze and N. Gulua, "Software Tools for Some Natural Language Texts Computer Processing," Computer Technology and Application, vol. 3, no. 3, pp. 219-225, March 2012.

[4] J. Antidze and N. Gulua, "Machine Translation from Georgian Language into Another," in Proc. I. Vekua Institute of Applied Mathematics, vol. 57, pp. 21-34, 2007.

[5] A. Shanidze, The Grammar of Georgian Language, Tbilisi, Georgia, 1930.

[6] D. MelikiShvili, The System of Georgian Verbs Conjugation, Tbilisi, Georgia: Logos Press, 2001

[7] D. Melikishvili, The Georgian Verb: A Morphosyntactic Analysis, New York, USA: Dunwoody Press, 2008.

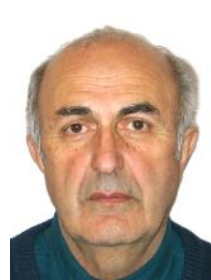

Jemal Antidze was born in Tbilisi, Georgia on March 10, 1935. He graduated from The Tbilisi State University, in 1958, mathematician, $\mathrm{PhD}$ degree in mathematics was earned at The Tbilisi State University, 1966, fields of study - software engineering and computer linguistics.

$\mathrm{He}$ was head of Systemic Programming Department, director of Institute of mathematics and information technology. Now, he is a professor of The Tbilisi State University, has more than 90 scientific publications.

Prof. Antidze is a senior member of IACSIT, an expert of UNESCO in informatics, a redactor in-chief of LNSE, a member of the scientific counsil of I.Vekua Scientific Institute of Applied Mathematics of The Tbilisi State University , Tbilisi, Georgia. For more information about him, please, visit the web site: http://fpv.science.tsu.ge/

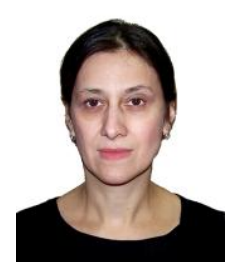

Nana Gulua was born in Sokhumi, Georgia on Dec. 13, 1968. He graduated from The Sokhumi State University, in 1994, mathematician. $\mathrm{PhD}$ degree in computer science was earned at The Tbilisi State University, Georgia, in 1999, fields of study software engineering and computer linguistics.

She is a full professor of The Mathematics and Computer Science Faculty at The Sokhumi State University. She has more than 30 scientific publications.

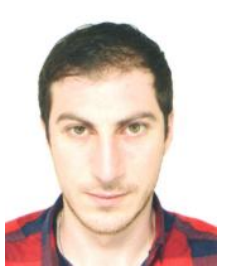

Irakli Kardava was born in Sokhumi, Georgia on Nov. 01, 1967. He graduated from Sokhumi State University with a master degree in computer science, 2012.

$\mathrm{He}$ is a $\mathrm{PhD}$ student of software engineering at The Sokhumi State University. He has 3 scientific publications. 